\title{
Decreasing Amphetamine-Induced Dopamine Release by Acute Phenylalanine/Tyrosine Depletion: A PET/ [ ' C]Raclopride Study in Healthy Men
}

\author{
Marco Leyton ${ }^{1,2, *}$, Alain Dagher ${ }^{2}$, Isabelle Boileau' ${ }^{2}$ Kevin Casey', Glen B Baker ${ }^{3}$, Mirko Diksic ${ }^{2}$, Roger \\ Gunn', Simon N Young' and Chawki Benkelfat ${ }^{1,2}$ \\ 'Department of Psychiatry, McGill University, Montréal, Québec, Canada; ${ }^{2}$ Department of Neurology \& Neurosurgery, McGill University, \\ Montréal, Québec, Canada; ${ }^{3}$ Department of Psychiatry, Mackenzie Centre, University of Alberta, Edmonton, Alberta, Canada
}

\begin{abstract}
Acute phenylalanine/tyrosine depletion (APTD) has been proposed as a new method to decrease catecholamine neurotransmission safely, rapidly, and transiently. Validation studies in animals are encouraging, but direct evidence in human brain is lacking. In the present study, we tested the hypothesis that APTD would reduce stimulated dopamine (DA) release, as assessed by positron emission tomography (PET) and changes in [ ' $\mathrm{C}$ ] raclopride binding potential (BP), a measure of DA D2/D3 receptor availability. Eight healthy men received two PET scans, both following d-amphetamine, $0.3 \mathrm{mg} / \mathrm{kg}$, p.o., an oral dose known to decrease [ ' $\mathrm{C}$ ]raclopride BP in ventral striatum. On the morning before each scan, subjects ingested, in counter-balanced order, an amino-acid mixture deficient in the catecholamine precursors, phenylalanine, and tyrosine, or a nutritionally balanced mixture. Brain parametric images were generated by calculating [ [ ' C] raclopride BP at each voxel. BP values were extracted from the $t$-map (threshold: $t=4.2$, equivalent to $p<0.05$, Bonferroni corrected) and a priori identified regions of interest from each individual's coregistered magnetic resonance images. Both receptor parametric mapping and region of interest analyses indicated that $\left[{ }^{1}\right.$ ' C] raclopride binding was significantly different on the two test days in the ventral striatum (peak $t=6.31 ; x=-25, y=-8$, and $z=0.1$ ). In the $t$-map defined cluster, [ ' $\mathrm{C}]$ raclopride BP values were $11.8 \pm 11.9 \%$ higher during the APTD session $(p<0.05)$. The reduction in $d$-amphetamine-induced DA release exhibited a linear association with the reduction in plasma tyrosine levels $(r=-0.82, p<0.05)$. Together, the results provide the first direct evidence that APTD decreases stimulated DA release in human brain. APTD may be a suitable new tool for human neuropsychopharmacology research.

Neuropsychopharmacology (2004) 29, 427-432, advance online publication, 29 October 2003; doi: I 0.1 038/sj.npp. 1300328
\end{abstract}

Keywords: dopamine; [ ' C]raclopride; catecholamine; tyrosine depletion

\section{INTRODUCTION}

The acute phenylalanine/tyrosine depletion (APTD) method was recently developed as a new tool to investigate the effects of catecholamine neurotransmission in humans (Moja et al, 1996; Sheehan et al, 1996; Leyton et al, 2000b). Initial studies suggest that APTD decreases subjective effects of amphetamine (McTavish et al, 1999b;

A preliminary report based on this study was presented at the Annual Meeting of the American College of Neuropsychopharmacology, San Juan, Puerto Rico, December 8-12, 2002

*Correspondence: M Leyton, Department of Psychiatry, McGill University, 1033 Pine Avenue West, Montreal, Quebec, Canada H3A IAI, Tel: + I-5|4-398-5804, Fax: + |-5 |4-398-4866,

E-mail: marco.leyton@mcgill.ca

Received 05 April 2003; revised 27 August 2003; accepted 02 September 2003

Online publication: 3 September 2003 at http://www.acnp.org/ citations/Npp09030303 I52/default.pdf
Rot et al, 2003), amphetamine-induced changes in impulse control (Rot et al, 2003), alcohol self-administration in social drinkers (Leyton et al, 2000a), withdrawal-related craving in nicotine-dependent smokers (Casey et al, 2002), and mood both in healthy subjects (Leyton et al, 2000b; Harmer et al, 2001) and manic patients (McTavish et al, 2001).

An assumption in these studies is that APTD is inducing functionally significant decreases in brain catecholamine synthesis. Animal studies support this possibility. APTD decreases post-mortem tissue concentrations of the dopamine (DA) metabolites homovanillic acid (HVA) and dihydroxyphenylacetic acid (Biggio et al, 1976), amphetamine-induced DA release (McTavish et al, 1999a), and cerebrospinal fluid (CSF) concentrations of HVA and the norepinephrine (NE) metabolite, 3-methoxy-4-hydroxyphenethyleneglycol (Palmour et al, 1998). In humans, though, the evidence remains circumstantial: APTD is reported to decrease blood pressure (Moja et al, 1996) and increase 
circulating levels of prolactin (Harmer et al, 2001), but direct evidence of decreased catecholamine transmission in brain is lacking.

In the present study, we sought to assess whether APTD would reduce stimulated DA release in human striatum, as measured by positron emission tomography (PET) and $\left[{ }^{11} \mathrm{C}\right]$ raclopride. Healthy subjects were administered a nutritionally balanced (BAL) amino-acid (AA) mixture containing the catecholamine precursors, phenylalanine and tyrosine, and, on a separate day, the phenylalanine/ tyrosine-deficient mixture. Ingestion of the latter mixture induces protein synthesis, leading to a transient reduction in the availability of phenylalanine and tyrosine for entry into the brain. Since the rate-limiting enzyme in catecholamine synthesis, tyrosine hydroxylase, is normally incompletely saturated (Carlsson and Lindqvist, 1978), reduced availability of the AA precursors decreases DA and NE synthesis. On both test days, subjects received a low oral dose of $d$-amphetamine $(0.3 \mathrm{mg} / \mathrm{kg}$, p.o.). We recently reported that this dose of $d$-amphetamine decreases $\left[{ }^{11} \mathrm{C}\right]$ raclopride binding potential (BP), and does so preferentially in the ventral striatum (Leyton et al, 2002). We predicted that APTD would attenuate the ability of $d$ amphetamine to elicit DA release, as reflected by higher $\left[{ }^{11} \mathrm{C}\right]$ raclopride BP values on the APTD vs BAL test day.

\section{METHODS}

\section{Subjects}

Eight healthy men (age, $23.1 \pm 3.6$ years; weight, $72.1 \pm 10.9 \mathrm{~kg}$ ) were recruited from advertisements placed in local newspapers and on campus. All were healthy nonsmokers, as determined by a physical exam, standard laboratory tests, and an interview using the Structured Clinical Interview for DSM-IV (First et al, 1995). None had a first-degree relative history of axis I psychiatric disorders as assessed by Research Diagnostic Criteria for Family Histories (Andreasen et al, 1977). On each day of the study, all tested negative on a urine drug screen sensitive to cocaine, opiates, phencyclidine, barbiturates, $\Delta^{9}$-tetrahydrocannabinol, benzodiazepines, and amphetamines (Triage ${ }^{\mathrm{TM}}$ Panel for Drugs of Abuse, Biosite Diagnostics ${ }^{\mathcal{C}}$, San Diego, CA, USA). The study was carried out in accordance with the Declaration of Helsinki and was approved by the Montreal Neurological Institute's Research Ethics Board.

\section{Procedure}

The day before each AA mixture test session, subjects ate a low protein diet provided by the investigators, and fasted from midnight. On the test day, subjects arrived at 0830 and had blood samples drawn to measure plasma AA concentrations. They then ingested one of the AA mixtures given in counter-balanced order. The APTD mixture's composition, preparation, and administration is based on our $100 \mathrm{gm}$ nutritionally balanced mixture with phenylalanine and tyrosine withheld (Young et al, 1985; Leyton et al, 2000b). Following ingestion of the mixture, participants remained awake in a room with videos, television, and reading material available to them. On both test days, an oral dose of $d$-amphetamine (Dexedrine, $0.3 \mathrm{mg} / \mathrm{kg}$ ) was administered approximately $1.5 \mathrm{~h}$ before tracer injection (mean $\pm \mathrm{SD}$, $1.4 \pm 0.5 \mathrm{~h}$ ) and $3.5 \mathrm{~h}$ after administration of the AA mixture $(3.6 \pm 0.5 \mathrm{~h})$.

Subjects underwent two scans on separate days between 1400 and 1700 on a Siemens ECAT HR + PET scanner (maximum resolution $4.1 \times 4.1 \times 4.5 \mathrm{~mm}^{3}$, full-width halfmaximum in center of field of view in air) with lead septa removed. At $1 \mathrm{~h}$ before tracer injection, a catheter was inserted into the subject's antecubital vein. Immediately before tracer injection, transmission scans were performed using ${ }^{68} \mathrm{Ga}$ for attenuation correction. Approximately, $10 \mathrm{mCi}$ of $\left[{ }^{11} \mathrm{C}\right]$ raclopride was injected as an intravenous (i.v.) bolus and data were acquired for $60 \mathrm{~min}$ in time frames of progressively longer duration.

High-resolution $(1 \mathrm{~mm})$ T1-weighted magnetic resonance (MR) images were obtained for all subjects (3D fast-field echo scans with 160 slices, $1 \mathrm{~mm}$ isotropic resolution, $\mathrm{TR}=18 \mathrm{~ms}, \mathrm{TE}=10 \mathrm{~ms}$, flip angle $=30^{\circ}$ ). These volumes were corrected for image intensity nonuniformity (Sled et al, 1998), and linearly and nonlinearly transformed into standardized stereotaxic space (Talairach and Tournoux, 1988) using automated feature matching to the MNI305 template (Collins et al, 1994b; Collins and Evans, 1997). Each individual's MRI was then coregistered to their summed radioactivity PET images (Evans et al, 1992). Inspection of the time activity curves suggested that one subject moved during one scan. Movement correction was made by applying an algorithm that corrects for betweenframe misalignment due to head movement. This coregistration method realigns each PET frame to a ligand-specific, MRI-derived, four-dimensional template, which represents radiotracer spatial distribution at each time point (Sechet et al, 2002; Reilhac et al, 2003).

PET images were reconstructed with a filtered backprojection using a $6 \mathrm{~mm}$ full-width half-maximum Hanning filter. Parametric images were generated by calculating $\left[{ }^{11} \mathrm{C}\right]$ raclopride $\mathrm{BP}\left(\mathrm{BP}=B_{\text {Avail }} / K_{\mathrm{D}} ; B_{\text {Avail }}=\right.$ density of available receptors) at each voxel, using a simplified reference tissue compartmental model with cerebellar activity as the reference (Lammertsma and Hume, 1996; Gunn et al, 1997). $T$-maps were then constructed, representing $t$-tests of change in $\left[{ }^{11} \mathrm{C}\right]$ raclopride $\mathrm{BP}$ between the two conditions; the voxel-by-voxel comparisons assessed the same voxels for every subject (Aston et al, 2000). Clusters of statistically significant change were identified by thresholding the $t$-map at a value of $t \geqslant 4.2$, which corresponds to $p<0.05$ corrected for multiple comparisons and a search volume of the entire striatum (Worsley et al, 1996).

BP values for each subject were extracted from the volume delineated by $t$-values greater than or equal to 4.2, as well as from five anatomical regions of interest (ROI). Identifying the ROI entailed three steps. First, each tissue type (gray matter, white matter, and CSF) was automatically classified (Collins et al, 1998). Second, the striatum was delineated from a probabilistic brain atlas (Collins et al, 1994a). Third, the study's ROI were drawn within the striatum's boundaries, based on the functional organization of limbic, associative, and sensory motor subcompartments as proposed by Laruelle, Haber, and co-workers (Haber and McFarland, 1999; Mawlawi et al, 2001; Martinez et al, 2003) (Figure 1): ventral striatum (limbic striatum), precommissural dorsal caudate (posterior caudate/associative striatum), 


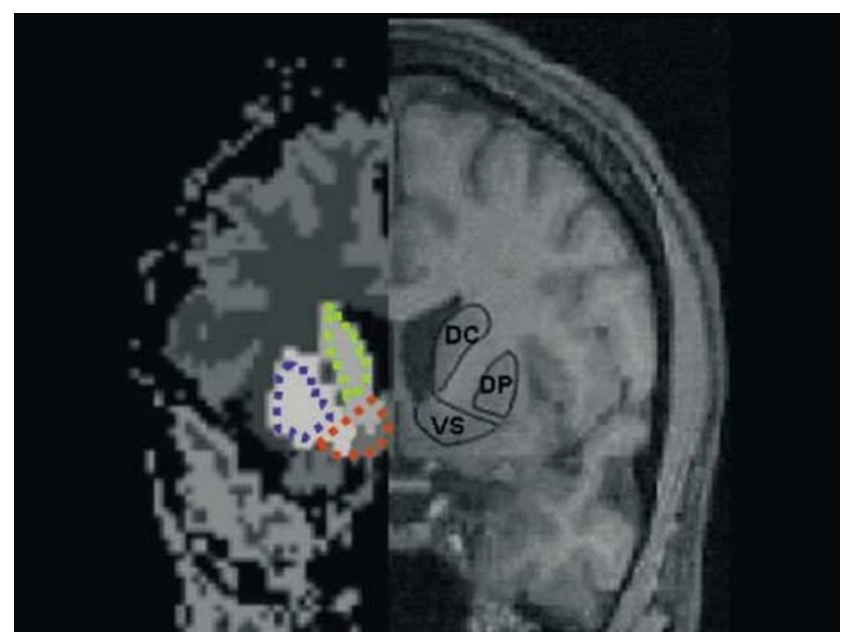

Figure I Depicted is a schematic representation of $\mathrm{ROI}$, as defined by Mawlawi et al (200l). On the left, the ROI are delineated by ANIMALINSECT segmentation (Collins and Evans, 1997) $8 \mathrm{~mm}$ rostral to the anterior commissure. On the right, hand drawn $\mathrm{ROI}$ are superimposed over an averaged MRI, coronal plane $(x=8)$. VS: limbic ventral striatum, composed of the nucleus accumbens and both the ventral putamen and ventral caudate rostral to the anterior commissure; DP: sensory motor dorsal putamen; DC: associative dorsal caudate.

precommissural dorsal putamen (posterior putamen/associative striatum), postcommissural caudate (anterior caudate/associative striatum), and postcommissural putamen (anterior putamen/sensory motor putamen). The ROI were drawn on each subject's MRI to match their individual neuroanatomy, and the same regions were used for both the first and second scans. Corrections for partial volume effects were not made. For the analyses, left and right hemispheres were combined. In all, 10 consecutive $1 \mathrm{~mm}$ slices drawn in the cerebellum served as the reference region.

\section{Plasma AA and Amphetamine Levels}

Blood samples were drawn at morning baseline before AA mixture ingestion and 5 and $6 \mathrm{~h}$ later. Phenylalanine and tyrosine were measured using precolumn derivatization with $o$-phthalaldehyde and gradient reverse-phase HPLC with aminoadipic acid as an internal standard and fluorometric detection. Plasma concentrations of amphetamine were analyzed with electron-capture gas chromatography after extraction and derivatization of amphetamine with pentafluorobenzenesulfonyl chloride (Asghar et al, 2002). Morning plasma samples were missing from three subjects, afternoon samples from one.

\section{Statistics}

Plasma and $\left[{ }^{11} \mathrm{C}\right]$ raclopride $\mathrm{BP}$ data were analyzed by ANOVA. Correlations were calculated with Pearson's correlation coefficient.

\section{RESULTS}

APTD lowered plasma concentrations of phenylalanine and tyrosine, as reflected by significant AA mixture $\times$ time interactions (tyrosine: $\mathrm{F}(1,4)=36.94, p<0.004$; phenylalanine: $\mathrm{F}(1,4)=36.83, \quad p<0.004)$. Compared to morning baseline, APTD decreased phenylalanine and tyrosine levels by $77.8 \pm 10.2$ and $73.0 \pm 8.3 \%$, respectively (mean $\pm S D$, $p<0.05)$. The BAL mixture, which contained phenylalanine and tyrosine, increased plasma levels of these AA by $71.9 \pm 53.0$ and $135.2 \pm 56.5 \%(p \leqslant 0.01)$ (Table 1). Amphetamine bioavailability did not differ on the two test days (BAL: $13.1 \pm 6.2$; APTD: $13.2 \pm 6.4 \mathrm{ng} / \mathrm{ml} ; p>0.95$ ).

Receptor parametric mapping indicated that on the two test sessions there were statistically significant differences in $\left[{ }^{11} \mathrm{C}\right]$ raclopride $\mathrm{BP}$ in the ventral striatum (peak, $t=6.31$; $x=-25, y=-8$, and $z=0$ ) (Figure 2). A $t$-test comparing $\left[{ }^{11} \mathrm{C}\right]$ raclopride BP values extracted from this $t$-map defined region confirmed the significant difference; $B P$ values were $11.8 \pm 11.9 \%$ higher on the APTD than BAL test day $(t=2.90, \mathrm{df}=7, p<0.03)$ (Table 2). In the five ROI, planned comparisons suggested an effect of AA mixture specific to the ventral striatum $(p \leqslant 0.02)$ and posterior putamen $(p \leqslant 0.01)$, although the AA mixture $\times$ ROI interaction was not significant $(\mathrm{F}(4,28)=1.98, p \leqslant 0.12)$ (Table 2$)$.

The magnitude of decrease in $\left[{ }^{11} \mathrm{C}\right]$ raclopride $\mathrm{BP}$ correlated with plasma tyrosine levels following APTD (Figure 3). Significant correlations were seen in the $t$-map

Table I Plasma Concentrations of Phenylalanine and Tyrosine Before and $5 \mathrm{~h}$ After Ingesting the AA Mixture

\begin{tabular}{lcc}
\hline Amino acid & Morning baseline & Postmixture \\
\hline Phenylalanine $(\mu \mathrm{mo} / /)$ balanced & $43.8 \pm 1.4$ & $75.4 \pm 23.6 * * *$ \\
Phenylalanine $(\mu \mathrm{mol} / \mathrm{l})$ APTD & $45.8 \pm 3.6$ & $10.5 \pm 4.8^{* * *}$ \\
Tyrosine $(\mu \mathrm{mo} / /)$ balanced & $55.4 \pm 8.0$ & $131.7 \pm 45.2^{* * *}$ \\
Tyrosine $(\mu \mathrm{mo} / /)$ APTD & $54.1 \pm 8.6$ & $15.3 \pm 5.3^{*}$ \\
\hline
\end{tabular}

Planned comparisons, ${ }^{*} p<0.05$, , $* * 0.01$.

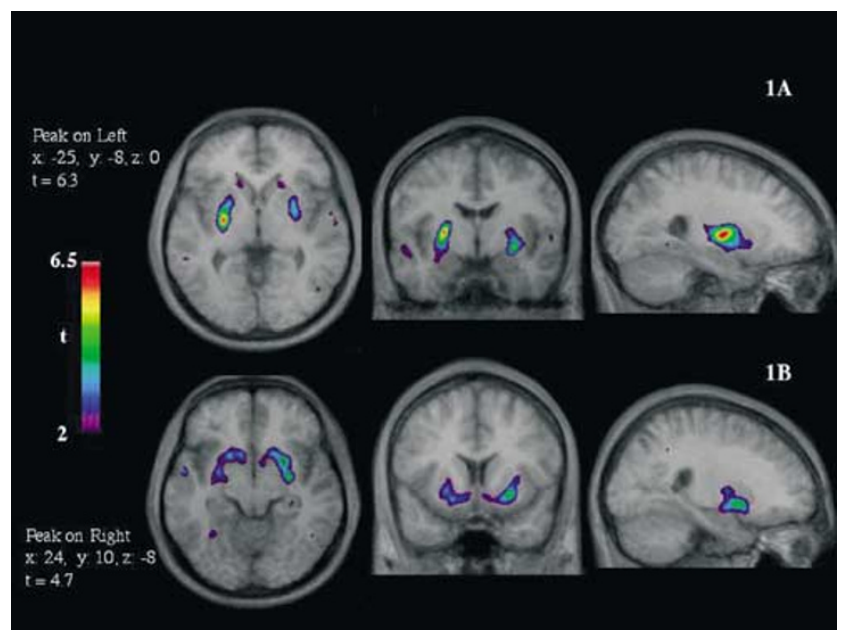

Figure 2 T-map depicting differences in [ $\left.{ }^{1} \mathrm{C}\right]$ raclopride BP between test sessions with the phenylalanine/tyrosine-deficient vs nutritionally balanced amino-acid mixture. The t-map is superimposed on an averaged MRI. Right side on right. (a) Orthogonal projections intersecting at the peak effect in the left striatum (top). (b) Peak effect in the right striatum (bottom). Coordinates in $\mathrm{MNI}$ space. 
Table 2 [ ' C]Raclopride Binding Potential Values (Mean \pm SD) on Test Days Following Ingestion of a Nutritionally Balanced or Phenylalanine/Tyrosine-Deficient (APTD) Amino-Acid Mixture

\begin{tabular}{|c|c|c|c|c|c|c|}
\hline Test day & $t$-map & Ventral striatum & Posterior putamen & Anterior putamen & Anterior caudate & Posterior caudate \\
\hline Balanced & $1.99 \pm 0.3$ & $1.13 \pm 0.2$ & $1.72 \pm 0.2$ & $1.68 \pm 0.3$ & $1.71 \pm 0.2$ & $0.80 \pm 0.1$ \\
\hline APTD & $2.21 \pm 0.2^{*}$ & $1.22 \pm 0.2^{*}$ & $1.81 \pm 0.2^{*}$ & $1.75 \pm 0.2$ & $1.72 \pm 0.2$ & $0.78 \pm 0.1$ \\
\hline \% Difference & $11.8 \pm 11.9$ & $8.4 \pm 21.2$ & $5.9 \pm 9.6$ & $4.5 \pm 9.6$ & $0.2 \pm 6.8$ & $-2.0 \pm 7.4$ \\
\hline
\end{tabular}

$t$-map values are from the region delineated by $t \geqslant 4.2$. Different from balanced mixture, $* p<0.05$.

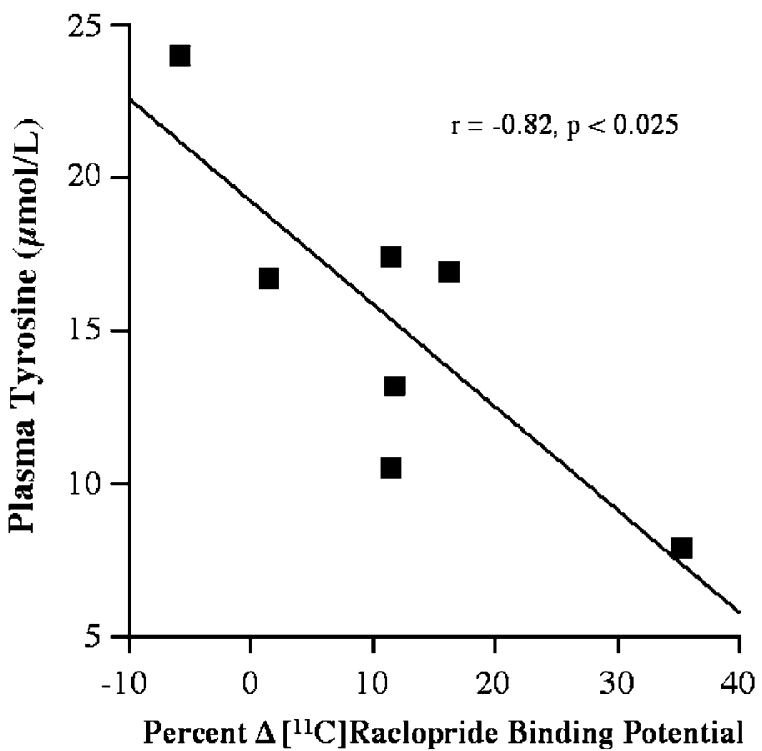

Figure 3 Correlation between plasma levels of tyrosine, following phenylalanine/tyrosine depletion, and the ability of $d$-amphetamine to elicit DA release. Note that plasma data were missing for one subject. In this individual, catecholamine depletion increased $\left[{ }^{19} \mathrm{C}\right]$ raclopride binding by I I. $3 \%$ in the t-map.

$(r=-0.82, p<0.025)$, in the ventral striatum $(r=-0.76$, $p<0.05)$, and in both anterior $(r=-0.77, p<0.05)$ and posterior putamen $(r=-0.80, p<0.04)$. In comparison, the association was not seen in either anterior $(r=-0.38$, $p>0.39)$ or posterior caudate $(r=-0.14, p>0.76)$.

\section{DISCUSSION}

The present study suggests that acute depletion of the catecholamine precursors, phenylalanine and tyrosine, attenuates the ability of $d$-amphetamine to elicit DA release in the ventral striatum. To our knowledge, these results provide the first evidence that APTD decreases stimulated DA release in human brain.

The effect of APTD on $d$-amphetamine-induced changes in striatal $\left[{ }^{11} \mathrm{C}\right]$ raclopride $\mathrm{BP}$ was restricted to limbic and associative subcompartments, as defined by Laruelle, Haber, and co-workers (Haber and McFarland, 1999; Mawlawi et al, 2001; Martinez et al, 2003). This agrees with previous observations that $d$-amphetamine preferentially decreases $\left[{ }^{11} \mathrm{C}\right]$ raclopride $\mathrm{BP}$ in these regions (Drevets et al, 2001; Leyton et al, 2002; Martinez et al, 2003). Animal studies suggest that this reflects regional differences in drug-induced increases in synaptic DA levels (Di Chiara and Imperato, 1988) rather than an artifact of the PET method. Mechanisms proposed to mediate this preferential effect include regional variability in DA release, and in the density and activity of DA transporters and DA cell innervation (Haber and McFarland, 1999; Wu et al, 2001).

A reanalysis of previously published data (Leyton et al, 2002) indicates that, in the region identified here, $d$ amphetamine $(0.3 \mathrm{mg} / \mathrm{kg}$, p.o.), compared to placebo, reduces $B P$ values by $12.7 \%$. Although one might conclude that APTD nearly completely prevented this effect (11.8/ $12.7=92.9 \%$ ), differences in the two studies caution against a direct comparison. For example, different individuals participated in the two protocols, there is substantial interindividual variability in both $\left[{ }^{11} \mathrm{C}\right]$ raclopride $\mathrm{BP}$ and amphetamine-induced changes in $\left[{ }^{11} \mathrm{C}\right]$ raclopride $\mathrm{BP}$, and ingesting a BAL mixture prior to receiving $d$-amphetamine might be different from receiving the psychostimulant without the AA mixture.

The ability of APTD to decrease plasma levels of tyrosine correlated with the attenuation of $d$-amphetamine-induced DA release. Linear regression analyses suggest that the association between plasma tyrosine levels and the ability of $d$-amphetamine to release DA has a steep slope (eg $y=-0.34 x+19.27$ : equation for plasma tyrosine $v s$ percent change in $\left[{ }^{11} \mathrm{C}\right]$ raclopride BP in the $t$-map). The steepness of slope may be accounted for by the fact that tyrosine hydroxylase is typically $75 \%$ saturated with tyrosine (Carlsson and Lindqvist, 1978). The Michaelis-Menten curve suggests that modest decreases in tyrosine availability would have limited effects on the enzyme's hydroxylation rate; below a certain level, though, hydroxylation would be expected to plummet. The present study suggests that APTD can achieve the necessary level of depletion.

The effect of APTD on $\left[{ }^{11} \mathrm{C}\right]$ raclopride BP is similar to the effect of the tyrosine hydroxylase inhibitor, $\alpha$-methyl-paratyrosine $(\alpha \mathrm{MPT})$. In a study conducted in non-human primates, $d$-amphetamine $(0.3 \mathrm{mg} / \mathrm{kg}, \quad$ i.v. $)$ decreased $\left[{ }^{123} \mathrm{I}\right] \mathrm{IBZM}$ binding by $25 \%$; this effect was reduced to $-12 \%$ when $d$-amphetamine administration was preceded by $\alpha$ MPT (Laruelle et al, 1997b).

The APTD method has a number of advantages as a tool to decrease catecholamine neurotransmission. For example, $\alpha \mathrm{MPT}$ requires repeated administration and a minimum of 3 days in-hospital observation (Verhoeff et al, 2001); its administration can induce crystalluria (Brogden et al, 1981) and acute dystonic reactions (McCann et al, 1990). In comparison, APTD can induce measurable effects within $3 \mathrm{~h}$ 
(McTavish et al, 2001; Casey et al, 2002), is not associated with severe side effects, and does not require overnight observation. A potential disadvantage of APTD is that, like $\alpha \mathrm{MPT}$, it appears to decrease both DA and NE synthesis (Palmour et al, 1998). However, recent behavioral data suggest that it may be possible to distinguish between dopaminergic and noradrenergic effects based on which are prevented by the immediate DA precursor, L-3,4-dihydroxyphenylalanine (Casey et al, 2002; Rot et al, 2003). Studies in rodents suggest that a variant of the APTD mixture containing seven instead of 14 AAs might decrease DA synthesis selectively (McTavish et al, 1999b), but this remains a subject of ongoing investigation.

The results of the present study should be interpreted in light of the following considerations. First, a two-by-two factorial design would have permitted us to assess more directly the size of APTD's effect on $d$-amphetamineinduced DA release. Restrictions on permitted radiation exposure precluded conducting four scans in the same individuals. However, the primary objective of the current study was to assess whether stimulated DA release is less when subjects are pretreated with APTD as compared to BAL. The results indicate that this occurs. Second, the sample size is modest $(n=8)$; however, it is within the norms for assessing effects of pharmacological challenges within subjects and the effect exceeds $p<0.05$, Bonferroni corrected. The correlations were obtained with only seven subjects, but the association is consistent with the presumed mechanism of action for APTD. Third, the drug that was administered to stimulate DA release, $d$-amphetamine, was given p.o. rather than i.v. Oral drug administration is associated with lower and more variable bioavailability (Angrist et al, 1987; Ylitalo, 1991). Nonetheless, plasma levels of amphetamine did not differ on the two test sessions, and we have previously shown that the dose used here induces significant decreases in $\left[{ }^{11} \mathrm{C}\right]$ raclopride BP in ventral striatum (Leyton et al, 2002). Fourth, the increased $\left[{ }^{11} \mathrm{C}\right]$ raclopride BP on the APTD test session might have reflected an upregulation of DA D2 receptors. $\alpha \mathrm{MPT}$ increases striatal binding of $\left[{ }^{11} \mathrm{C}\right]$ raclopride (Verhoeff $e t$ al, 2001), [ $\left.{ }^{123} \mathrm{I}\right] \mathrm{IBZM}$ (Laruelle et al, 1997a), and [ $\left.{ }^{123} \mathrm{I}\right]$ epidepride (Fujita et al, 2000). However, these changes are thought to reflect $\alpha \mathrm{MPT}$-induced decreases in synaptic DA levels. Autoradiography studies in rats indicate that $\alpha \mathrm{MPT}$ does not alter striatal DA D2 receptor $K_{\mathrm{D}}$ or $B_{\max }$ (Laruelle et al, 1997a). Fifth, catecholamines can affect cerebral blood flow, and the present results could reflect altered delivery or washout of the tracer. However, simulation studies indicate that even large changes in blood flow have negligible effects on receptor ligand binding, as measured by the method used here (Aston et al, 2000). Sixth, the present study did not evaluate whether APTD would decrease extracellular DA levels in the absence of a challenge. Some evidence suggests that the effects of APTD are more pronounced under challenge conditions. In microdialysis studies, APTD diminishes $d$-amphetamine-induced increases in DA release without affecting extracellular DA levels at predrug resting baseline (McTavish et al, 1999b). Larger effects under challenge conditions might reflect the fact that tyrosine hydroxylase activity is regulated, in part, by intraneuronal catecholamine stores (Ames et al, 1978). Lowered stores, due to catecholamine release, would be expected to increase tyrosine hydroxylase activity, making DA synthesis more vulnerable to lowered tyrosine availability. Our previous studies suggest that behavioral effects of APTD might also be seen more consistently under challenge conditions (Leyton et al, 2000b; Rot et al, 2003). Seventh, the PET $\left[{ }^{11} \mathrm{C}\right]$ raclopride method is unable to detect extrastriatal changes in DA release, and the effect of APTD in these other regions is unknown. Finally, both the behavioral and neurochemical effects of tryptophan-deficient AA mixtures might be larger in women than in men (Young and Leyton 2002); whether this is true for APTD remains to be assessed.

In conclusion, the present study indicates that APTD decreases stimulated DA release in human striatum. The observation validates the method in human brain, and suggests that APTD is a suitable new tool for neuropsychopharmacology research in humans.

\section{ACKNOWLEDGEMENTS}

This work was supported by two operating grants from the Canadian Institutes of Health Research, MOP-36429 to ML, $\mathrm{CB}$, and $\mathrm{AD}$, and MOP-49480 to $\mathrm{AD}$. ML, and $\mathrm{CB}$ who are recipients of salary awards from Fonds de la Recherche en Santé du Québec (FRSQ). We thank Rick Fukusawa, Dean Jolly, Mirjana Kovacevic, Francine Lenoff, Shadreck Mzengeza, Gary Sauchuk, Gail Rauw, and Francine Weston for excellent technical assistance, and Dr Robert Lisbona, Chief of Nuclear Medicine at the MNI, for valuable help during the PET scans.

\section{REFERENCES}

Ames MM, Lerner P, Lovenberg W (1978). Tyrosine hydroxylase. Activation by protein phosphorylation and end product inhibition. J Biol Chem 253: 27-31.

Andreasen NC, Endicott J, Spitzer RL, Winokur G (1977). The family history method using diagnostic criteria: reliability and validity. Arch Gen Psychiatry 34: 1229-1235.

Angrist B, Corwin J, Bartlik B, Cooper T (1987). Early pharmacokinetics and clinical effects of oral $d$-amphetamine in normal subjects. Biol Psychiatry 22: 1357-1368.

Asghar SJ, Baker GB, Rauw GA, Silverstone PH (2002). A rapid method of determining amphetamine in plasma samples using pentafluorobenzenesulfonyl chloride and electron-capture gas chromatography. J Pharmacol Toxicol Methods 46: 111-115.

Aston JA, Gunn RN, Worsley KJ, Ma Y, Evans AC, Dagher A (2000). A statistical method for the analysis of positron emission tomography neuroreceptor ligand data. NeuroImage 12: 245-256.

Biggio G, Porceddu ML, Gessa GL (1976). Decrease of homovanillic, dihydroxyphenylacetic acid and cyclic-adneosine- $3^{\prime}, 5^{\prime}$ monophosphate content in the rat caudate nucleus induced by the acute administration of an amino acid mixture lacking tyrosine and phenylalanine. J Neurochem 26: 1253-1255.

Brogden RN, Heel RC, Speight TM, Avery GS (1981). Methyl-ptyrosine: a review of its pharmacology and clinical use. Drugs 21: 81-89.

Carlsson A, Lindqvist M (1978). Dependence of 5HT and catecholamine synthesis on concentrations of precursor amino acids in rat brain. Naunyn Schmiedebergs Arch Pharmacol 303: 157-164.

Casey K, Benkelfat C, Young SN, Weston F, Rivard M-E, Leyton M (2002). Catecholamine depletion reduces nicotine withdrawal related craving but not self-administration in nicotine dependent 
smokers. In: American College of Neuropsychopharmacology San Juan, Puerto Rico. 9-12 December.

Collins DL, Evans AC (1997). ANIMAL: validation and applications of non-linear registration-based segmentation. Int J Pattern Recognition Artif Int 11: 1271-1294.

Collins DL, Holmes CJ, Peters TM, Evans AC (1994a). Automated 3-D volume-based segmentation. Hum Brain Mapp 3: 190-208.

Collins DL, Neelin P, Peter TM, Evans AC (1994b). Automated 3D intersubject registration of MR volumetric data in standardized Talairach space. J Comput Assist Tomogr 18: 192-205.

Collins DL, Zijdenbos A, Kollokian V, Sled JG, Kabani NJ, Holmes CJ et al (1998). Design and construction of a realistic digital brain phantom. IEEE Trans Med Imaging 17: 463-468.

Di Chiara G, Imperato A (1988). Drugs abused by humans preferentially increase synaptic dopamine concentrations in the mesolimbic system of freely moving rats. Proc Natl Acad Sci 85: 5274-5278.

Drevets WC, Gautier C, Price JC, Kupfer DJ, Kinahan PE, Grace AA et al (2001). Amphetamine-induced dopamine release in human ventral striatum correlates with euphoria. Biol Psychiatry 49: 81-96.

Evans AC, Marrett S, Neelin P, Collins L, Worsley K, Dai W et al (1992). Anatomical mapping of functional activation in stereotactic coordinate space. NeuroImage 1: 43-53.

First MB, Spitzer RI, Gibbon M (1995). Axis I Disorders. New York State Psychiatric Institute: New York.

Fujita M, Verhoeff NP, Varrone A, Zoghbi SS, Baldwin RM, Jatlow PA et al (2000). Imaging extrastriatal dopamine D(2) receptor occupancy by endogenous dopamine in healthy humans. Eur $J$ Pharmacol 387: 179-188.

Gunn RN, Lammertsma AA, Hume SP, Cunningham VJ (1997). Parametric imaging of ligand-receptor binding in PET using a simplified reference region model. NeuroImage 6: 279-287.

Haber SN, McFarland NR (1999). The concept of the ventral striatum in nonhuman primates. Ann NY Acad Sci 877: 33-48.

Harmer CJ, McTavish SFB, Clark L, Goodwin GM, Cowen PJ (2001). Tyrosine depletion attenuates dopamine function in healthy volunteers. Psychopharmacology 154: 105-111.

Lammertsma AA, Hume SP (1996). Simplified reference tissue model for PET receptor studies. NeuroImage 4: 153-158.

Laruelle M, D'Souza CD, Baldwin RM, Abi-Dargham A, Kanes SJ, Fingado CL et al (1997a). Imaging $\mathrm{D}_{2}$ receptor occupancy by endogenous dopamine in humans. Neuropsychopharmacology 17: $162-174$.

Laruelle M, Iyer RN, al-Tikriti MS, Zea-Ponce Y, Malison R, Zoghbi SS et al (1997b). Microdialysis and SPECT measurements of amphetamine-induced dopamine release in nonhuman primates. Synapse 25: 1-14.

Leyton M, Boileau I, Benkelfat C, Diksic M, Baker G, Dagher A (2002). Amphetamine-induced increases in extracellular dopamine, drug wanting and novelty seeking: a PET $/\left[{ }^{11} \mathrm{C}\right]$ raclopride study in healthy men. Neuropsychopharmacology 27: 1027-1035.

Leyton M, Young SN, Blier P, Baker GB, Pihl RO, Benkelfat C (2000a). Acute tyrosine depletion and alcohol ingestion in healthy women. Alcohol: Clin Exp Res 24: 459-464.

Leyton M, Young SN, Pihl RO, Etezadi S, Lauze C, Blier P et al (2000b). Effects on mood of acute phenylalanine/tyrosine depletion in healthy women. Neuropsychopharmacology 22: 52-63.

Martinez D, Slifstein M, Broft A, Mawlawi O, Hwang D-R, Huang T et al (2003). Imaging human mesolimbic dopamine transmission with PET: II. Amphetamine-induced dopamine release in the functional subdivisions of the striatum. J Cereb Blood Flow Metab 23: 285-300.

Mawlawi O, Martinez D, Slifstein M, Broft A, Chatterjee R, Hwang DR et al (2001). Imaging human mesolimbic dopaminergic transmission with positron emission tomography; accuracy and precision of DA2 receptor measurements in ventral striatum. J Cereb Blood Flow Metab 21: 1034-1055.

McCann UD, Penetar DM, Belenky G (1990). Acute dystonic reaction in normal humans caused by catecholamine depletion. Clin Neuropharmacol 13: 565-568.

McTavish SF, Cowen PJ, Sharp T (1999a). Effect of a tyrosine-free amino acid mixture on regional brain catecholamine synthesis and release. Psychopharmacology (Berl) 141: 182-188.

McTavish SFB, McPherson MH, Harmer CJ, Clark L, Sharp T, Goodwin GM et al (2001). Antidopaminergic effects of dietary tyrosine depletion in healthy subjects and patients with manic illness. Br J Psychiatry 179: 356-360.

McTavish SFB, McPherson MH, Sharp T, Cowen PJ (1999b). Attenuation of some subjective effects of amphetamine following tyrosine depletion. J Psychopharmacol 13: 144-147.

Moja EA, Lucini V, Benedetti F, Lucca A (1996). Decrease in plasma phenylalanine and tyrosine after phenylalanine-tyrosine free amino acid solutions in man. Life Sci 58: 2389-2395.

Palmour RM, Ervin FR, Baker GB, Young SN (1998). Effects of acute tryptophan depletion and acute tyrosine/phenylalanine depletion on CSF amine metabolite levels and voluntary alcohol consumption in vervet monkeys. Psychopharmacology 136: 1-7. Reilhac A, Sechet S, Boileau S, Gunn R, Evans AC, Dagher A (2003). Motion correction for PET ligand imaging. In: Human Brain Mapping Abstract New York. 18 June.

Rot MAH, Benkelfat C, Young SN, Baker GB, Leyton M (2003). Role of dopamine $v s$ norepinephrine in effects of $d$-amphetamine: an acute phenylalanine/tyrosine depletion study in healthy men. In: Canadian College of Neuropsychopharmacology Montreal, Canada. 1-4 June.

Sechet S, Reilhac A, Gunn R, Evans AC, Dagher A (2002). Frame misalignment induced errors in PET studies: an investigation of strategies for correction. IEEE Nuclear Science Symposium and Medical Imaging Conference, Norfolk, VA 10-16 November 2002. Sheehan BD, Tharyan P, McTavish SFB, Campling GM, Cowen PJ (1996). The use of dietary manipulation to deplete plasma tyrosine and phenylalanine in healthy subjects. J Psychopharmacol 10: 231-234.

Sled JG, Zijdenbos A, Evans AC (1998). A nonparametric method for automatic correction of intensity nonuniformity in MRI data. IEEE Trans Med Imaging 17: 87-97.

Talairach J, Tournoux P (1988). Co-Planar Stereotactic Atlas of the Human Brain. Thieme: Stuttgart.

Verhoeff NPLG, Kapur S, Hussey D, Lee M, Christensen B, Papatheodorou $G$ et al (2001). A simple method to measure baseline occupancy of neostriatal dopamine D2 receptors by dopamine in vivo in healthy subjects. Neuropsychopharmacology 25: $213-223$.

Wu Q, Reith ME, Kuhar MJ, Carroll FL, Garris PA (2001). Preferential increases in nucleus accumbens dopamine after systemic cocaine administration are caused by unique characteristics of dopamine neurotransmission. J Neurosci 21: 6338-6347.

Worsley KJ, Marrett S, Neelin P, Vandal AC, Friston KJ, Evans AC (1996). A unified statistical approach for determining significant signals in images of cerebral activation. Hum Brain Mapp 4: 58-73.

Ylitalo P (1991). Effect of exercise on pharmacokinetics. Ann Med 23: $289-294$.

Young SN, Leyton M (2002). The role of serotonin in human mood and social interaction: Insight from altered tryptophan levels. Pharmacol Biochem Behav 71: 857-865.

Young SN, Smith SE, Pihl RO, Ervin FR (1985). Tryptophan depletion causes a rapid lowering of mood in normal males. Psychopharmacology 87: 173-177. 